Tapia, M. (2019) Modern Chicano Street Gangs: Ethic Pride Versus «Gangsta» Subculture. Hispanic Journal of Behavioral Sciences, vol. 41(3), pp. 312-330.

Topalli, V. (2005) When Being Good is Bad. An Expansion of Neutralization Theory. Criminology, vol. 43, pp. 797-835.

Submission date: 12.09 .2019$.

Сорокин Олег Владимирович - кандидат социологических наук, старший научный сотрудник Центра социологии молодежи Института социально-политических исследований РАН; доцент Высшей школы современных социальных наук Московского государственного университета имени М. В. Аомоносова. Адрес: 119333, Россия, г. Москва, ул. Фотиевой, д. 6. к. 2; 119991, ГСП-1, г. Москва, Аенинские горы, А. 1, стр. 13. Тел.: +7 (499) 530-28-84; +7 (495) 939-36-29. Эл. aspec: ov.sorokin@gmail.com

Sorokin Oleg Vladimirovich, Candidate of Sociology, Senior Research Fellow, Center for Sociology of Youth, RAS Institute of Socio-Political Research; Associate Professor, Higher School of Modern Social Sciences, Lomonosov Moscow State University. Postal address: 6, Bldg. 2, Fotievoy St., Moscow, Russian Federation, 119333; GSP-1, 1, Bldg. 13, Leninskiye Gory, Moscow, 119991. Tel.: +7 (499) 530-28-84; +7 (495) 939-36-29. E-mail: ov.sorokin@gmail.com

DOI: $10.17805 /$ zpu.2019.4.9

\title{
Влияние повседневности на частоту самоубийств *
}

\author{
П. А. КОРОТКОВ \\ ПОВОЛЖСКИЙ ГОСУДАРСТВЕННЫЙ ТЕХНОЛОГИЧЕСКИЙ УНИВЕРСИТЕТ, \\ А. Б. ТРУБЯНОВ \\ МАРИЙСКИЙ ГОСУДАРСТВЕННЫЙ УНИВЕРСИТЕТ, \\ E. А. ЗАГАЙНОВА \\ КАЗАНСКИЙ (ПРИВОЛЖСКИЙ) ФЕДЕРАЛЬНЫЙ УНИВЕРСИТЕТ
}

В статье представлен авторский подход к изучению влияния повседневности на частоту самоубийств. Повседневность рассматривается в качестве фактора самоубийства, комплексно отражающего социально-экономические условия. Анализируется соотношение основных видов повседневной деятельности (труда, быта и досуга) с позиций концепций суицидального поведения.

Показано, что для повседневной жизни работающих по найму свойственен типический конфликт работы и остальной (личной, семейной и общественной) жизни, или рабочего и внерабочего времени. Этот конфликт - решающий фактор суицидальных проявлений. Увеличение продолжительности рабочего времени, с одной стороны, структурирует жизнь, предупреждая скуку и тревогу, с другой - препятствует удовлетворению обыденных потребностей. В свою очередь, продолжительность видов деятельности во внерабочее время отражает тесноту связи с другими людьми (фактор снижения риска самоубийства), а также социальную изоляцию и одиночество (факторы повышения риска самоубийства). Анализируется схема функциональной организации целенаправленного поведения в повседневной жизни: «работа - остальная жизнь».

* Исследование выполнено при финансовой поддержке РФФИ в рамках научного проекта № 19-010-00830.

The reported study was funded by RFBR according to the research project № 19-010-00830. 
Выдвигается основная гипотеза исследования: использование времени в сферах труда, быта и досуга работающими по найму оказывает значимое влияние на частоту самоубийств при данных общих социально-экономических условиях. Также формулируются гипотезы-следствия, которые позволяют развить исследование.

Ключевые слова: самоубийство; повседневная жизнь; работающие по найму; рабочее время; внерабочее время

\section{ВВЕАЕНИЕ}

$\mathbf{R}$ опрос установления взаимосвязей самоубийства с социально-экономическими условиями изучается более века (Аюркгейм, 1994). На индивидуальном уровне влияние социально-экономических условий на самоубийство достаточно хорошо изучено (Stack, 2000). Вместе с тем на агрегированном уровне взаимосвязи самоубийства с социально-экономическим факторами, как правило, носят аспектный и противоречивый характер. К примеру, доход (Magnusson, Mäkinen, 2010), безработица (Chen et al., 2012; Jalles, Andresen, 2014) и уровень образования (Гилинский, 20111) могут влиять на частоту самоубийств как положительно, так и отрицательно. Такая противоречивость не позволяет корректно оценивать тенденции изменения частоты самоубийств при изменении большинства известных социально-экономических показателей. Аля построения компактных моделей, удовлетворительно объясняющих и прогнозирующих изменения частоты самоубийств, требуются новые, более информативные социально-экономические показатели.

Как сложившиеся, так и трансформирующиеся (экономический кризис, безработица, ухудшение материального положения населения и др.) социально-экономические условия отражаются на повседневной деятельности населения (Патрушев, 2005; Российская повседневность ... , 2009). Это позволяет рассматривать повседневность в качестве интегрального фактора самоубийства (Коротков, Загайнова, 2019), комплексно отражающего социально-экономические условия. При этом самоубийство рассматривается как относительно массовое социальное явление (Гилинский, 2011). Ежегодно более 800000 человек по всему миру лишают себя жизни. Самоубийство вторая ведущая причина смерти среди молодых людей 15-29 лет². Россия входит в первую тройку государств с самыми высокими показателями самоубийств на душу населения, а по числу суицидов среди мужчин является мировым лидером³.

Основной метод изучения и операционализации повседневности - бюджет времени. Продолжительность деятельности - это весьма точный показатель образа жизни людей и изменений их реального поведения в сферах труда, быта и досуга (Патрушев, 2005). Эмпирические исследования позволили установить количественные соотношения между частотой самоубийств и продолжительностью рабочего времени (Коротков, Загайнова, 2017), а также выявить виды деятельности в сферах быта и досуга, которые вносят значимый вклад в изменчивость частоты самоубийств (Коротков, Загайнова, 2019). Однако характер установленных соотношений теоретически недостаточно конкретизирован. Соответственно, цель данной статьи - выявить и обобщить теоретические основы связи самоубийства с повседневностью для развертывания на их основе системы гипотез исследования.

\section{РОАЬ КОНЦЕПЦИЙ СУИЦИАААЬНОГО ПОВЕАЕНИЯ В ИССАЕАОВАНИИ СВЯЗИ «САМОУБИЙСТВО - ПОВСЕАНЕВНОСТЬ»}

Рассмотрим существующие концепции суицидального поведения сквозь призму представления о связи самоубийства с повседневностью. 
Согласно концепции А. Г. Абрумовой, решающий фактор суицидальных проявлений - конфликт двух или нескольких разнонаправленных тенденций, одну из которых составляет актуальная потребность человека, а другую - тенденция, препятствующая ее удовлетворению (Абрумова, Тихоненко, 1980).

В повседневной жизни работающие по найму испытывают типический конфликт «работа - остальная жизнь», или «рабочее - внерабочее время» (Коротков, Загайнова, 2019). Работающие по найму должны трудиться, «отчуждать» свой труд, чтобы жить. Работа, выступая средством жизни, одновременно является для нее препятствием, ибо жизнь начинается только тогда, когда трудовая деятельность прекращается. Аействительно, увеличение продолжительности рабочего времени пропорционально сокращает внерабочее время, необходимое для удовлетворения большинства актуальных потребностей. Это приводит к ухудшению качества личной и семейной жизни, возникновению личностно-семейных конфликтов (ухудшение взаимоотношений со значимыми близкими, недостаток внимания и заботы со стороны окружающих, сексуальные проблемы, социальная изоляция и др.), под влиянием которых совершается около $2 / 3$ всех самоубийств. Кроме того, увеличение продолжительности рабочего времени повышает вероятность конфликтов в профессиональной сфере, что также может мотивировать суицидальное поведение. Предметным подтверждением связи самоубийства и переработки выступает феномен «каро-хисацу» (самоубийство от переработки), который впервые начали официально регистрировать в Японии в конце 1990-х гг. (Waters, 2015). При этом самоубийства от переработки не определяются конкретными рабочими местами, профессией или географическим положением.

Вместе с тем избыток внерабочего, прежде всего свободного, времени или недостаток рабочего времени вызывают неудовлетворенность и переживание дисбаланса жизненных сфер, поскольку работа помогает структурировать время (Баланс работы ..., 2016). Обычным практическим методом структурирования времени является взаимодействие в первую очередь с материальной стороной внешней реальности: то, что обычно называют работой (Берн, 1988: 4). В тяжелые периоды неструктурированного времени человек испытывает скуку или тревогу. Негативные переживания скуки или тревоги являются одной из причин самоубийства (Юрьева, 2006). По сведениям ВО3, в 1,5\% случаев ведущей причиной суицидов является «пресыщенность жизнью»: скука, разочарование жизнью.

Таким образом, избыток, равно как и недостаток рабочего времени, могут приводить к увеличению частоты самоубийств. Аействительно, эмпирический анализ зависимости частоты самоубийств от продолжительности рабочего времени с учетом скрытых факторов (социальных, экономических и др.), выполненный нами на панельных данных для 22 европейских стран за период с 1998 по 2012 г., выявил нелинейную - параболическую - тенденцию изменения частоты самоубийств (Коротков, Загайнова, 2017). Оптимальное значение продолжительности рабочей недели, при котором достигается минимум самоубийств, составило 38,7 часа.

Н. Фейбероу и Э. Шнейдман рассматривали одиночество и чувство изолированности от общества как наиболее значимые факторы самоубийства (Farberow, Shneidman, 1961). П. Сорокин показал, что рост самоубийств зависит от одиночества личности, ее оторванности или отчуждения от общества, представляющих результат дезорганизованного общества (Сорокин, 2003). По сведениям ВОЗ, вклад одиночества в мотивы самоубийства составляет 6,5\% (Юрьева, 2006; Предотвращение самоубийств ..., 2014: 39). 
Снижение интенсивности общения между людьми, рост одиночества и оторванности личности от общества проявляются в изменении использования времени в сферах быта и досуга. Это позволяет рассматривать продолжительность видов деятельности во внерабочее время как фактор риска или снижения риска самоубийства. Эмпирически нами установлено, что продолжительность ухода за членами семьи, волонтерства, посещения мероприятий, естественным образом отражающих связь с другими людьми, отрицательно связана с частотой самоубийств, а продолжительность покоя и отдыха, работы по дому, по хозяйству, отражающих социальную изоляцию и одиночество, - положительно (Коротков, Загайнова, 2019).

В эпоху глобального капитализма работающие по найму обычно вовлекаются руководством в акты жестокости, направленные на устранение слабых или непродуктивных работников. По С. Сассену, глобальный капитализм движется за счет новой логики вытеснения тех, кто считается непригодным или лишним для удовлетворения экономических потребностей (Sassen, 2014). В то время как послевоенная фордистская экономика была всеобъемлющей и привела людей в коллективные пространства общественной жизни, глобальный капитализм имеет тенденцию насильственно изгонять их. Рабочее место из пространства социальной солидарности и классовой идентичности превратилось в пространство насилия и изгнания. В этих условиях увеличение продолжительности рабочего времени может рассматриваться как фактор риска самоубийства, поскольку отражает нарастание отчуждения между людьми.

Концепция суицидального поведения И. П. Павлова базируется на понятии рефлекса цели - прототипе мотивации достижения цели. Рефлекс цели - стремление к обладанию определенным раздражающим предметом, понимая и обладание, и предмет в широком смысле слова (Павлов, 1973: 214). К основным факторам, определяющим плодотворность проявления рефлекса цели, относятся его периодичность и напряжение - существование препятствий на пути к достижению цели. По Павлову, отсутствие цели - основная причина самоубийства многих людей. Это утверждение созвучно взглядам В. Франкла, который видел главную причину самоубийства в отсутствии у человека смысла жизни (Франкл, 1990).

Современные физиологи әкспериментально установили, что стремление к достижению цели обусловлено скоростью достижения цели и ее ценностью (Кузнецова, Кузьмина, Радченко, 2006; Кузнецова, Горбачева, 2012). Алительное, стереотипное предъявление эмоционально значимых положительных раздражителей (высокой скорости приближающегося объекта-цели) вызывает «скучание» и развитие монотонии, ведущие к снижению мотивации достижения цели (Горбачева, 2010). В свою очередь, отставление во времени достижения цели в конечном счете ведет к снижению мотивации вплоть до полного отказа от достижения цели независимо от ее ценности. При этом ценность цели все-таки способна компенсировать отрицательное воздействие низких скоростей до определенного момента.

Концепция суицидального поведения И. П. Павлова и ее развитие использовались авторами при анализе схемы функциональной организации целенаправленного поведения в повседневной жизни «работа - остальная жизнь» с позиции суицидологии (Коротков, 2017).

Полагая, что цель повседневной жизни - удовлетворение обыденных материальных и духовных потребностей, главным образом во внерабочее время (быт и досуг), а труд - деятельность, направленная на достижение цели, можно рассматривать работу как оставление во времени достижения цели, а внерабочее время - как цель по- 
вседневной жизни, ценность которой характеризуется структурой и содержанием внерабочего времени. Такое описание соотношения работы и остальной жизни является схематичным, но вполне применимым для анализа повседневной жизни работающих по найму. Безусловно, люди могут иметь глобальные цели, лежащие за пределами повседневного существования, но тогда труд становится не средством, а целью, т. е. первой жизненной потребностью. В этом случае человек живет, чтобы трудиться, утверждается в труде. Работающий по найму априори не свободен: он трудится для того, чтобы жить.

В рамках указанной схемы чрезмерное увеличение продолжительности рабочего времени - отставление во времени достижения цели - может приводить к отказу от достижения цели или отказу от жизни, т. е. к самоубийству. При этом непродолжительное рабочее время или полное его отсутствие, т. е. высокая скорость достижения цели, могут вызывать «скучание» и развитие монотонии (пресыщения), которые также мотивируют суицидальное поведение. Эти предположения подтверждаются результатами әмпирического анализа зависимости частоты самоубийств от продолжительности рабочего времени с учетом скрытых факторов (Коротков, Загайнова, 2017).

Ценность жизни может компенсировать негативное влияние переработки и (или) недоработки на частоту самоубийств. Согласно П. Сорокину, жизнь личности приобретает в ее глазах общественную ценность и общественный смысл в тесных отношениях с другими людьми и активном участии в общественной жизни (Сорокин, 2003). Бессмысленная жизнь сама по себе является причиной самоубийства (Франкл, 1990). Э. Шнейдман писал, что противоядием от одиночества является дружба и аффилиация, а жизнь в изоляции не представляет никакого интереса даже для злого Рока (Шнейдман, 2001: 119). Отсюда чем продолжительнее виды деятельности во внерабочее время, отражающие тесноту связей с другими людьми, тем ценнее жизнь, а чем продолжительнее виды деятельности, характеризующие степень социальной изоляции и одиночества, тем ее ценность ниже. Связь указанных видов деятельности во внерабочее время, опосредующих ценность жизни, и частоты самоубийств также эмпирически подтверждается (Коротков, Загайнова, 2019).

\section{ВЫАВИЖЕНИЕ ГИПОТЕЗ}

Поскольку мы не располагаем специальной социологической теорией зависимости частоты самоубийств от повседневности, то общая гипотеза исследования формулируется на основе результатов анализа роли концепций суицидального поведения в изучении связи «самоубийство - повседневность» и авторского подхода к объяснению данной связи.

Основная гипотеза - использование времени в сферах труда, быта и досуга работающими по найму оказывает значимое влияние на частоту самоубийств при данных общих социально-экономических условиях. Аанная гипотеза согласуется с рассмотренными концепциями.

Исходя из теоретического характера связи частоты самоубийств и продолжительности видов деятельности в сферах труда (параболическая связь), быта и досуга формулируется цепочка выводных гипотез-следствий.

1. Между частотой самоубийств и средней продолжительностью рабочего времени работающих по найму независимо от пола существует параболическая (U-образная) зависимость, предполагающая наличие оптимума рабочего времени, при котором наблюдается минимальное значение частоты самоубийств. 
2. Временной диапазон рабочих часов, включающий оптимум рабочего времени, является «переломным»: в «переломном» диапазоне с ростом доли отработавших рабочие часы частота самоубийств снижается, а в неоптимальных диапазонах (до и после «переломного») - имеет другой знак, т. е. растет.

3. С ростом доли работающих по найму, отработавших короткие (меньше 9 часов в неделю) или длинные (больше 50 часов в неделю) рабочие часы, частота самоубийств растет.

4. С ростом средней продолжительности видов деятельности в сферах быта и досуга, отражающих тесноту связи между людьми, частота самоубийств снижается, а с ростом средней продолжительности видов деятельности, отражающих социальную изоляцию и одиночество, увеличивается.

Первая и четвертая гипотезы уже прошли первичную проверку (Коротков, Загайнова, 2017, 2019). Однако требуется их систематическое исследование на более полных и детализированных российских и европейских панельных данных.

Вторая и третья гипотезы логически связаны и призваны дать дополнительные основания для принятия первой гипотезы. В связи с тем что использование средних значений продолжительности рабочего времени может маскировать различия в распределении рабочих часов, планируется использовать показатели доли работников, работающих менее 9, 25-29, 30-34, 35-39, более 50 часов и в других доступных официальной статистике временных диапазонах.

Принятие четвертой гипотезы также требует дополнительного основания. Аля этого планируется оценить влияние степени включенности работающих по найму в виды деятельности в сферах быта и досуга на частоту самоубийств. Задача состоит в том, чтобы на основе анализа статистических данных установить и описать характер связей между частотой самоубийств и степенью включенности и попытаться определить сравнительный «вес» (значимость) видов деятельности с точки зрения их влияния на частоту самоубийств.

Аля представления данных о затратах времени и включенности в различные виды деятельности будут использоваться рекомендации по гармонизации европейских обследований использования времени Европейской статистической комиссии. Высший уровень классификации составляют шесть разделов, характеризующих основные направления деятельности: рабочее время и время, связанное с работой; ведение домашнего хозяйства (неоплачиваемая работа); личный уход; свободное время; обучение; другое. Аанные разделы детализируются на подразделы. Например, свободное время включает: участие в мероприятиях, посещение или прием друзей, просмотр телепередач и прослушивание радио дома и др.

Затраты времени и включенность работающих по найму в различные виды деятельности целесообразно относить к неделе. Использование недели в качестве отчетного периода обосновано тем, что противопоставление рабочего и внерабочего времени, лежащее в основе выдвигаемых гипотез, при существующей организации труда в полной мере проявляется именно в течение недели, когда большинство обыденных потребностей реализуются в выходные дни после окончания рабочей недели.

\section{ЗАКАЮЧЕНИЕ}

Самоубийство как многофакторный социальный феномен комплексно зависит от особенностей текущей исторической ситуации: социально-экономических, социально-политических и культурных условий проживания населения. Как сложившиеся, 
так и трансформирующиеся (экономический кризис, безработица, ухудшение материального положения населения и др.) социально-экономические условия отражаются на реальном поведении населения - повседневной деятельности. Повседневность операционализируется с помощью бюджета времени. Зная продолжительность и структуру видов повседневной деятельности, можно оценить влияние условий проживания населения на частоту самоубийств.

Авторский подход к исследованию самоубийства под влиянием повседневности применительно к работающим по найму базируется на условном противопоставлении основных сфер повседневности: работы и остальной жизни (быта и досуга). Аействительно, пока труд не превратился в первую жизненную потребность, для работающих по найму он является не целью, а средством удовлетворения обыденных потребностей, пространством принуждения и отчуждения, забирающим ценное время личной, семейной и общественной жизни. В этих условиях рабочее время характеризует трудность задачи, или отставление во времени достижения цели - свободной от принудительного труда жизни, а внерабочее время и его структура характеризуют ценность этой жизни.

Предложенные теоретические основания самоубийства согласуются с социальными концепциями суицидального поведения и физиологическими механизмами функциональной организации целенаправленного поведения. На основе указанных концепций и авторского подхода сформулированы основная и выводные гипотезы относительно связи частоты самоубийств с использованием времени населением в сферах труда, быта и досуга.

\section{ПРИМЕЧАНИЯ}

1 А также: Малянов A. (2004) Аепрессивные, зато богатые [Электронный ресурс] // Газета.Ру. 27 июля. URL: https://m.gazeta.ru/science/2011/07/27_a_3713181.shtml (дата обращения: 03.03.2019).

2 Вопросы здравоохранения. Самоубийства [Электронный ресурс]// Глобальный веб-сайт Всемирной организации здравоохранения. URL: https://www.who.int/mental_health/suicideprevention/infographic/ru/ (дата обращения: 15.02.2019).

3 Воронин Н. (2019) Россия - в тройке лидеров по числу самоубийств [Электронный ресурс]// BBC News. Русская служба. 9 сентября. URL: https://www.bbc.com/russian/news-49636376 (дата обращения: 15.09.2019).

\section{СПИСОК АИТЕРАТУРЫ}

Абрумова, А. Г., Тихоненко, В. А. (1980) Аиагностика суицидального поведения. М. : ХОЗУ Миннефтепрома. 55 с.

Баланс работы и личной жизни у сотрудников российского производственного предприятия (2016) / А. Н. Моспан, Е. Н. Осин, Т. Ю. Иванова, Е. И. Рассказова, В. В. Бобров // Организационная психология. Т. 6. № 2. С. 8-29.

Берн, Э. (1988) Игры, в которые играют люди. Психология человеческих взаимоотношений ; Аюди, которые играют в игры. Психология человеческой судьбы : пер. с англ. М. : Прогресс. 400 с.

Гилинский, Я. В. (2011) Самоубийство как социальный феномен // Социологический журнал. № 2. С. 39-48.

Горбачева, М. В. (2010) Сравнительный анализ психофизиологических показателей у детей и шимпанзе в процессе достижения цели : автореф. дис. ... канд. биол. наук. СПб. 20 с.

Аюркгейм, Э. (1994) Самоубийство: социологический этюд. М. : Мысль. 399 с.

Коротков П. А., Загайнова Е. А. (2017) Взаимосвязь уровня распространенности самоубийств и продолжительности рабочего времени // Статистика и экономика. Т. 14. № 4. C. 41-53. DOI: 10.21686/2500-3925-2019-4-26-34. 
Коротков, П. А. (2017) Теоретический подход к измерению актуальной мотивации социальной группы // Знание. Понимание. Умение. № 2. С. 221-236. DOI: 10.17805/zpu.2017.2.17.

Коротков, П. А., Загайнова, Е. А. (2019) Частота самоубийств и использование времени в сферах быта и досуга // Социологические исследования. №1. С. 106-115. DOI: 10.31857/ S013216250003752-0.

Кузнецова, Т. Г., Горбачева, М. В. (2012) Сравнительный анализ некоторых поведенческих реакций у детей и шимпанзе в процессе достижения ими цели с различной субъективной ценностью // Вестник Самарского университета. Естественнонаучная серия. № 3. С. 192-202.

Кузнецова, Т. Г., Кузьмина, В. Е., Радченко, М. В. (2006) Функциональная организация поведенческих реакций у детей дошкольного возраста в сложных условиях достижения цели // Вестник Самарского университета. Естественнонаучная серия. № 2 (42). С. 189-201.

Павлов, И. П. (1973) Авадцатилетний опыт объективного изучения высшей нервной деятельности (поведения) животных. М. : Наука. 661 с.

Патрушев, В. А. (2005) Аинамика использования бюджетов времени городским и сельским населением // Социологические исследования. № 8. С. 46-51.

Предотвращение самоубийств: глобальный императив (2014). Женева : Всемирная организация здравоохранения. 97 с.

Российская повседневность в условиях кризиса: взгляд социологов : аналитический доклад (2009) / науч. ред. Н. И. Покида. М. : Институт социологии РАН. 139 с.

Сорокин, П. А. (2003) Самоубийство как общественное явление // Социологические исследования. № 2. С. 104-115.

Франкл В. (1990) Человек в поисках смысла. М. : Прогресс. 364 с.

Шнейдман, Э. (2001) Ауша самоубийцы. М. : Смысл. 315 с.

Юрьева, А. Н. (2006) Клиническая суицидология. Анепропетровск : Пороги. 472 с.

Chen, J., Choi, Y. J., Mori, K., Sawada, Y., Sugano, S. (2012) Socio-economic studies on suicide: A survey // Journal of Economic Surveys. № 26 (2). P. 271-306.

Farberow, N., Shneidman, E. (1961) The cry for help. Blakiston Division, McGraw-Hill. 398 p.

Jalles, T., Andresen, A. (2014) Suicide and Unemployment: A Panel Analysis of Canadian Provinces // Archives of Suicide Research. № 18 (1). P. 14-27.

Magnusson, S., Mäkinen, IH. (2010) Sweden: Income and suicide// Psychological Reports. № 107 (1). P. 157-162.

Sassen, S. (2014) Expulsions. Brutality and Complexity in the Global Economy. Cambridge, MA: Harvard University Press. 298 p.

Stack, S. (2000) Sociological research into suicide // D. Lester (Ed.), Suicide prevention resources for the millennium. Philadelphia, PA : Brunner-Routledge. 336 p. P. 17-29.

Waters, S. (2015) Suicide as Protest in the French Workplace// Modern \& Contemporary France. № 23 (4). P. 491-510.

Aата поступления: 11.03.2019 2.

THE IMPACT OF EVERYDAY LIFE ON SUICIDE RATE

\author{
P. A. KOROTKOV \\ Volga State University of TeCHNology \\ A. B. TRUBYANOV \\ MARI STATE UNIVERSITY \\ E. A. ZAGAYNOVA \\ KAZAN FEDERAL UNIVERSITY
}

The paper introduces the author's conceptual approach to the study of the impact of everyday life on the suicide rate. In the framework of our research everyday life is considered as a suicide factor, which provides a holistic perspective on the social and economic conditions. The correlation between the basic everyday activities (labour, daily routine, leisure time) has been analyzed from the perspective of suicidal behavior. 
The research shows that the typical conflict between work and personal, family and social life, or in other words, work and off-work time is characteristic for wage earners. This conflict is a decisive factor in suicidal manifestations. On the one hand, the increase of working hours structures a person's life, thus reducing boredom and anxiety. On the other hand, long working hours prevent the fulfillment of everyday needs. The duration of activities outside working hours also reflects the close connection with other people (the factor reducing suicide risk), as well as social isolation and loneliness (factors increasing suicide risk). The scheme of the functional organization of goal-oriented behavior in everyday life - "work-life balance" is analyzed.

The main hypothesis of the study is the following - the use of time in the areas of work, life and leisure by employees has a significant impact on the frequency of suicides under given general social and economic conditions. The author also formulates the consequence hypotheses that allow the development of the research.

Keywords: suicide; everyday life; employees; work time; off-work time

\section{REFERENCES}

Abrumova, A. G. and Tihonenko, V. A. (1980) Diagnostika suicidal'nogo povedenija. Moscow, HOZU Minnefteproma. 55 p. (In Russ.).

Balans raboty i lichnoj zhizni u sotrudnikov rossijskogo proizvodstvennogo predprijatija (2016) / A. N. Mospan, E. N. Osin, T. Ju. Ivanova, E. I. Rasskazova, V. V. Bobrov. Organizacionnaja psibologija, vol. 6, no. 2, pp. 8-29. (In Russ.).

Berne, E. (1988) Igry, v kotorye igrajut ljudi. Psibologija chelovecheskib vzaimootnoshenij; Ljudi, kotorye igrajut v igry. Psibologija chelovecheskoj sud'by: Per. s angl. Moscow, Progress, 400 p. (In Russ.).

Gilinskij, Ja. V. (2011) Samoubijstvo kak social'nyj fenomen. Sociologicheskij zburnal, no. 2, pp. 39-48. (In Russ.).

Gorbacheva, M. V. (2010) Sravnitel'nyj analiz psibofiziologicheskib pokazatelej u detej i shimpanze $v$ processe dostizhenija celi: abstract of the diss. ... Candidate of Biology. St. Petersburg. 20 p. (In Russ.).

Durkheim, E. (1994) Samoubijstvo: sociologicheskij jetjud. Moscow, Mysl', 399 p. (In Russ.).

Korotkov P. A., Zagajnova E. A. (2017) Vzaimosvjaz' urovnja rasprostranennosti samoubijstv i prodolzhitel'nosti rabochego vremeni. Statistika i jekonomika, vol. 14, no. 4, pp. 41-53. (In Russ.).

Korotkov, P. A. (2017) Teoreticheskij podhod k izmereniju aktual'noj motivacii social'noj gruppy. Znanie. Ponimanie. Umenie, no. 2, pp. 221-236. (In Russ.).

Korotkov, P. A., Zagajnova, E. A. (2019) Chastota samoubijstv i ispol'zovanie vremeni v sferah byta i dosuga. Sociologicheskie issledovanija, no. 1, pp. 106-115. (In Russ.).

Kuznecova, T. G. and Gorbacheva, M. V. (2012) Sravnitel'nyj analiz nekotoryh povedencheskih reakcij u detej i shimpanze v processe dostizhenija imi celi s razlichnoj sub\#ektivnoj cennost'ju. Vestnik Samarskogo universiteta. Estestvennonauchnaja serija, no. 3, pp. 192-202. (In Russ.).

Kuznecova, T. G., Kuz'mina, V. E., Radchenko, M. V. (2006) Funkcional'naja organizacija povedencheskih reakcij u detej doshkol'nogo vozrasta v slozhnyh uslovijah dostizhenija celi. Vestnik Samarskogo universiteta. Estestvennonauchnaja serija, no. 2 (42), pp. 189-201. (In Russ.).

Maljanov, D. (2004) Depressivnye, zato bogatye. Gazeta.Ru [online] Available at: https://m.gazeta.ru/science/2011/07/27_a_3713181.shtml (accessed: 30.01.2018). (In Russ.).

Pavlov, I. P. (1973) Dvadcatiletnij opyt ob\#ektivnogo izuchenija vysshej nervnoj dejatel'nosti (povedenija) zhivotnyh. Moscow, Nauka Publ. 661 p. (In Russ.).

Patrushev V. D. (2005) Dynamics of time utilization by rural and urban population. Sociologicheskie Issledovaniya, no. 8, pp. 46-51. (In Russ.) Russ.).

Preventing suicide: a global imperative (2014). Geneva, World Health Organization. 97 p. (In

Rossijskaja povsednevnost' v uslovijab krizisa: vzgljad sociologov: analytical report (2009)/ ed. by N. I. Pokida. Moscow, Institute of Sociology of the Russian Academy of Sciences. 139 p. (In Russ.). 
Sorokin P. A. (2003) Suicide as a social phenomenon. Sociologicheskie Issledovaniya, no. 2, pp. 104-115. (In Russ.)

Frankl V. (1990) Chelovek v poiskah smysla. Moscow, Progress, 364 p. (In Russ.)

Shneidman, E. (2001) Dusha samoubijcy. Moscow, Smysl. 315 p. (In Russ.)

Yuryeva L. N. (2006) Clinical Suisidology. Dnipropetrovsk, Porogi, 472 p. (In Russ.)

Chen, J., Choi, Y. J., Mori, K., Sawada, Y., \& Sugano, S. (2012) Socio-economic studies on suicide: A survey. Journal of Economic Surveys, no. 26 (2), pp. 271-306.

Farberow, N., Shneidman, E. (1961) The cry for belp. Blakiston Division, McGraw-Hill. 398 p.

Jalles, T. and Andresen, A. (2014) Suicide and Unemployment: A Panel Analysis of Canadian Provinces. Archives of Suicide Research, no. 18 (1), pp. 14-27.

Magnusson, S, Mäkinen, IH. (2010) Sweden: Income and suicide. Psychological Reports, no. 107 (1), pp. 157-162.

Sassen, S. (2014). Expulsions. Brutality and Complexity in the Global Economy. Cambridge, MA, Harvard University Press, 298 p.

Stack, S. (2000). Sociological research into suicide. In D. Lester (Ed.), Suicide prevention resources for the millennium (pp. 17-29). Philadelphia, PA, Brunner-Routledge.

Waters, S. (2015). Suicide as Protest in the French Workplace. Modern \& Contemporary France, no. 23 (4), pp. 491-510.

Submission date: 11.03 .2019$.

Коротков Петр Анатольевич - кандидат экономических наук, доцент кафедры транспортно-технологических машин Поволжского государственного технологического университета, член Российской ассоциации статистиков. Адрес: 424000, Россия, г. Йошкар-Ола, пл. Аенина, А. 3. Тел.: +7 (8362) 30-49-51. Эл. адреc: korotkovpa@volgatech.net, korotp@bk.ru

Трубянов Алексей Борисович - кандидат биологических наук, доцент кафедры математического анализа и теории функций Марийского государственного университета. Адрес: 424000 , Россия, г. Йошкар-Ола, пл. Аенина, д. 1. Тел.: +7 (8362) 68-80-02. Эл. адреc: true47@mail.ru, trubyanov_ab@marsu.ru

Загайнова Екатерина Андреевна - студент магистратуры кафедры управления корпоративными финансами Казанского (Приволжского) федерального университета. Адрес: 420008, Россия, г. Казань, ул. Кремлевская, 18. Тел.+7 (906) 110-44-64. Эл. адрес: katenazag@yandex.ru, e.zagaynova@list.ru

Korotkov Pyotr Anatolyevich, Candidate of Economics, Associate Professor, Department of Transport and Technological Machines, Volga State University of Technology; Member, Russian Association of Statisticians. Postal address: 3, Lenina Sq., Yoshkar-Ola, Russian Federation, 424000. Tel.:+7 (8362) 30-49-51. E-mail: korotkovpa@volgatech.net, korotp@bk.ru

Trubyanov Aleksey Borisovich, Candidate of Biology, Associate Professor, Department of Mathematical Analysis and Theory of Functions, Mari State University. Postal address: 1, Lenina Sq., Yoshkar-Ola, Russian Federation, 424000. Tel.: +7 (8362) 68-80-02. E-mail: true47@mail.ru, trubyanovab@marsu.ru

Zagaynova Ekaterina Andreyevna, Graduate Student, Department of Corporate Finance Management, Kazan Federal University. Postal address: 18, Kremlyovskaya St., Kazan, Russian Federation, 420008. Tel.: +7 (906) 110-44-64. E-mail: katenazag@yandex.ru, e.zagaynova@list.ru 